\title{
Geographical trends in the yolk carotenoid composition of the pied flycatcher (Ficedula hypoleuca)
}

\author{
Tapio Eeva · Suvi Ruuskanen · Juha-Pekka Salminen · Eugen Belskii · Antero Järvinen • \\ Anvar Kerimov • Erkki Korpimäki · Indrikis Krams • Juan Moreno • Chiara Morosinotto • \\ Raivo Mänd · Markku Orell • Anna Qvarnström · Heli Siitari • Fred M. Slater • Vallo Tilgar • \\ Marcel E. Visser $\cdot$ Wolfgang Winkel $\cdot$ Herwig Zang $\cdot$ Toni Laaksonen
}

Received: 22 March 2010/Accepted: 25 August 2010/Published online: 17 September 2010

(c) Springer-Verlag 2010

\begin{abstract}
Carotenoids in the egg yolks of birds are considered to be important antioxidants and immune stimulants during the rapid growth of embryos. Yolk carotenoid composition is strongly affected by the carotenoid composition of the female's diet at the time of egg formation. Spatial and temporal differences in carotenoid availability may thus be reflected in yolk concentrations.
\end{abstract}

Communicated by Douglas Robinson.

T. Eeva $(\bowtie) \cdot$ S. Ruuskanen · E. Korpimäki · C. Morosinotto ·

T. Laaksonen

Section of Ecology, Department of Biology,

University of Turku, 20014 Turku, Finland

e-mail: tapio.eeva@utu.fi

\section{J.-P. Salminen}

Laboratory of Organic Chemistry and Chemical Biology,

University of Turku, Turku, Finland

E. Belskii

Institute of Plant and Animal Ecology,

Russian Academy of Sciences, Ekaterinburg, Russia

A. Järvinen

Kilpisjärvi Biological Station,

University of Helsinki, Helsinki, Finland

A. Kerimov

Zvenigorod Biological Station of Moscow State University,

Moscow, Russia

\section{Krams}

Institute of Systematic Biology,

Daugavpils University, Daugavpils, Latvia

\section{J. Moreno}

Departamento de Ecologia Evolutiva,

Museo Nacional de Ciencias Naturales (CSIC),

Madrid, Spain
To assess whether yolk carotenoid concentrations or carotenoid profiles show any large-scale geographical trends or differences among habitats, we collected yolk samples from 16 European populations of the pied flycatcher, Ficedula hypoleuca. We found that the concentrations and proportions of lutein and some other xanthophylls in the egg yolks decreased from Central Europe northwards. The most southern population (which is also the one found at the highest altitude) also showed relatively low carotenoid

R. Mänd · V. Tilgar

Department of Zoology, University of Tartu, Tartu, Estonia

M. Orell

University of Oulu, Oulu, Finland

A. Qvarnström

University of Uppsala, Uppsala, Sweden

H. Siitari

University of Jyväskylä, Jyväskylä, Finland

F. M. Slater

Cardiff University, Cardiff, UK

M. E. Visser

Netherlands Institute of Ecology (NIOO-KNAW),

Heteren, The Netherlands

W. Winkel

Institute of Avian Research "Vogelwarte Helgoland",

Wilhelmshaven, Germany

H. Zang

Goslar, Germany 
levels. Concentrations of $\beta$-carotene and zeaxanthin did not show any obvious geographical gradients. Egg yolks also contained proportionally more lutein and other xanthophylls in deciduous than in mixed or coniferous habitats. We suggest that latitudinal gradients in lutein and xanthophylls reflect the lower availability of lutein-rich food items in the northern $F$. hypoleuca populations and in montane southern populations, which start egg-laying earlier relative to tree phenology than the Central European populations. Similarly, among-habitat variation is likely to reflect the better availability of lutein-rich food in deciduous forests. Our study is the first to indicate that the concentration and profile of yolk carotenoids may show large-scale spatial variation among populations in different parts of the species' geographical range. Further studies are needed to test the fitness effects of this geographical variation.

Keywords Insectivorous birds - Lepidoptera larvae . Maternal effects · Tree phenology · Egg antioxidants

\section{Introduction}

Bird egg yolks are rich in carotenoids, such as lutein, zeaxanthin and $\beta$-carotene (Blount et al. 2000; Surai et al. 2001; Cassey et al. 2005). Yolk carotenoids are considered important antioxidants during the rapid growth of an embryo and important components for mounting a good immune response to infections (Surai et al. 2001; Saino et al. 2003; Biard et al. 2005; Koutsos et al. 2006). The carotenoid composition of the egg yolk is strongly affected by the environment, primarily the carotenoid composition of the female's diet at the time of egg formation (Partali et al. 1985; Surai et al. 2001; Blount et al. 2002; Biard et al. 2005; Török et al. 2007). Birds are found to transfer supplemented dietary carotenoids, like lutein, zeaxanthin and $\beta$-carotene, into egg yolk (see Remes et al. 2007 and references therein). These primary yolk carotenoids have further been shown to be transferred chemically unmodified from leaves via herbivorous insects to the females and their eggs of an insectivorous passerine, the great tit, Parus major (Partali et al. 1985). Since birds need to acquire all of their carotenoids from their food, carotenoid availability may be limited for females during the laying period (Hõrak et al. 2002; Saino et al. 2002; Blount et al. 2004; Biard et al. 2005). An important source of carotenoids for several insectivorous birds, like tits (Parids) and flycatchers (Ficedula sp.), are herbivorous insects like lepidopteran caterpillars, which are rich in carotenoids (Partali et al. 1985; Sillanpää et al. 2008; Eeva et al. 2010) and are often abundant during the breeding period of temperate insectivores, being an important component of the nestling diet of these birds (Gibb and Betts 1963; van Balen 1973; Perrins
1991; van Noordwijk et al. 1995; Sanz 1998; Eeva et al. 2005). Temporal and spatial variation in food quality may therefore also affect the yolk carotenoid content. For example, the concentration and profile of yolk carotenoids of the collared flycatcher Ficedula albicollis varied considerably between two breeding seasons with different caterpillar abundance (Hargitai et al. 2006). Correspondingly, spatial and temporal changes in invertebrate abundance within a breeding season were reflected in the plasma carotenoid concentrations of $P$. major nestlings (Sillanpää et al. 2009) and females (Tummeleht et al. 2006).

Different populations of a species may be at unequal positions in relation to carotenoid availability in different habitats or different parts of the species' geographical range. For example, many temperate birds, like the pied flycatcher, F. hypoleuca, start breeding at an earlier phenological stage of vegetation at northern latitudes as compared to more southern populations (Slagsvold 1975; Slagsvold 1976; Järvinen 1983). In northernmost Finland, $F$. hypoleuca starts laying at or even before the leafing of deciduous trees (Järvinen 1993; Eeva et al. 2000), while in Central Europe laying takes place 2-3 weeks after leafing (van Dongen et al. 1997; Both and Visser 2005). In central Spain, the laying period coincides with leafing by oaks, with most birds laying before leafing is completed (Sanz 2001; Sanz et al. 2003). Since temporal variation in caterpillar biomass is strongly dependent on tree phenology, birds at northern latitudes or in montane habitats may have to start laying at a lower ambient caterpillar abundance (Eeva et al. 2002), so they might have more limited access to dietary carotenoids than those of more southern (or lower elevation) populations. This might have fitness consequences for growing embryos or chicks, for example via changes in antioxidant or immune defense, hatchability, survival or sex ratio (McGraw et al. 2005). Currently, however, there are no studies on possible large-scale geographical differences in yolk carotenoid profiles.

We collected samples of egg yolks from 16 European populations of $F$. hypoleuca across a large part of the breeding range of this species in order to assess whether yolk carotenoid concentrations or carotenoid profiles show any large-scale geographical trends or differences among habitats. To our knowledge, this is the first time that a large-scale population-level approach has been used to study the variation in bird carotenoid levels. We hypothesized that, due to geographical variations in the match between $F$. hypoleuca laying time and tree and insect phenology, the eggs of northern (or higher elevation) populations would contain less carotenoids and/or show a different carotenoid profile from those of more southern (or lower elevation) populations. We also compared yolk carotenoid levels among deciduous, mixed and coniferous 
Table 1 Location, habitat types and sample sizes for $16 \mathrm{~F}$. hypoleuca populations where egg yolks were collected for carotenoid analyses in summer 2007

\begin{tabular}{|c|c|c|c|c|c|c|c|c|c|c|}
\hline Key & Country & Area & $\begin{array}{l}\text { Latitude } \\
\left({ }^{\circ} \mathrm{N}\right)\end{array}$ & $\begin{array}{l}\text { Longitude } \\
\left({ }^{\circ} \mathrm{E}\right)\end{array}$ & $\begin{array}{l}\text { Altitude } \\
\text { (m.a.s.l.) }\end{array}$ & Habitat & $\mathrm{N}$ & $\begin{array}{l}\text { Sample } \\
\text { collection } \\
\text { dates }\end{array}$ & $\begin{array}{l}\text { Estimated birch } \\
\text { leaf unfolding } \\
\text { dates }^{\mathrm{a}}\end{array}$ & $\begin{array}{l}\text { Birch leaf } \\
\text { unfolding } \\
\text { dates in } 2007\end{array}$ \\
\hline A & Spain & Lozoya & 41.0 & -3.8 & 1,400 & Deciduous & 10 & 11th May-31st May & - & - \\
\hline B & Germany & Harz & 51.9 & 10.6 & 498 & Deciduous & 10 & 1st May-22nd May & 18th Apr & - \\
\hline $\mathrm{C}$ & Netherlands & Buunderkamp & 52.0 & 5.8 & 30 & Mixed & 10 & 3rd May-8th May & 11th Apr & - \\
\hline $\mathrm{D}$ & UK & Powys & 52.2 & -3.5 & 195 & Deciduous & 10 & 8th May-10th May & 18th Apr & - \\
\hline $\mathrm{E}$ & Germany & Lingen & 52.5 & 7.3 & 35 & Coniferous & 10 & 30th Apr-14th May & 14th Apr & - \\
\hline $\mathrm{F}$ & Russia & Moscow & 55.7 & 36.9 & 167 & Coniferous & 10 & 21th May-28th May & 2nd May & 2nd May ${ }^{\mathrm{b}}$ \\
\hline G & Latvia & Krāslava & 55.9 & 27.0 & 156 & Coniferous & 10 & 24th May-28th May & 2nd May & - \\
\hline $\mathrm{H}$ & Russia & Revda & 56.8 & 59.6 & 372 & Mixed & 10 & 25th May-15th Jun & - & 18th May ${ }^{\mathrm{c}}$ \\
\hline I & Sweden & Oland & 57.1 & 17.0 & 7 & Mixed & 9 & 17th May-1st Jun & 2nd May & - \\
\hline $\mathrm{J}$ & Estonia (1) & Kilingi-Nõmme & 58.1 & 25.1 & 60 & Deciduous & 10 & 22nd May-25th May & 9th May & - \\
\hline $\mathrm{J}$ & Estonia (2) & Kilingi-Nõmme & 58.1 & 25.1 & 60 & Coniferous & 10 & 21st May-23rd May & 9th May & - \\
\hline $\mathrm{K}$ & Finland & Turku & 60.4 & 22.2 & 4 & Deciduous & 10 & 24th May-10th June & 9th May & 6th May ${ }^{\mathrm{d}}$ \\
\hline $\mathrm{L}$ & Finland & Harjavalta & 61.3 & 22.2 & 55 & Coniferous & 10 & 29th May-1st June & 12th May & 10th May ${ }^{\mathrm{e}}$ \\
\hline $\mathrm{M}$ & Finland & Kauhava & 63.0 & 23.0 & 54 & Coniferous & 10 & 28th May-6th June & 16th May & 18th May ${ }^{\mathrm{d}}$ \\
\hline $\mathrm{N}$ & Finland & Oulu & 65.1 & 25.6 & 20 & Mixed & 10 & 28th May-1st June & 22nd May & 22nd May ${ }^{\mathrm{d}}$ \\
\hline $\mathrm{O}$ & Norway & Skibotn & 69.3 & 20.7 & 120 & Coniferous & 10 & 2nd June-8th June & 30th May & 26th May ${ }^{\mathrm{f}}$ \\
\hline $\mathrm{P}$ & Finland & Kevo & 69.8 & 27.0 & 160 & Deciduous & 3 & 12th June-15th June & 5th June & 3rd June ${ }^{\mathrm{g}}$ \\
\hline
\end{tabular}

${ }^{a}$ Siljamo et al. 2008

b A. Kerimov, personal observation

${ }^{c}$ E. Belskii, personal observation

${ }^{\mathrm{d}}$ Finnish Forest Research Institute

e T. Eeva, personal observation

${ }^{\mathrm{f}}$ A. Järvinen, personal observation

g Kevo Subarctic Research Station

habitats, since these environments are known to differ in timing and abundance of carotenoid-rich food items, such as lepidopteran larvae (van Balen 1973). Since caterpillar abundance is generally found to be higher in deciduous forests, we also expected that carotenoid availability would be better in deciduous forests, and that this would be reflected in the yolk carotenoid level and composition.

\section{Materials and methods}

\section{Egg sampling}

Egg samples were collected from 16 different nest-box study populations across the breeding range of the pied flycatchers during spring and summer 2007 (Table 1; Fig. 1). The sampling area covers a large part of the breeding area of $F$. hypoleuca in Europe. In each population, the nest-boxes were checked regularly to monitor the progress of nesting. Since yolk carotenoid concentrations may vary systematically with laying order (Royle et al. 1999; Hõrak et al. 2002), we standardized our sampling by collecting the eggs in the middle of the laying sequence. When eggs were found in the nest, they were marked, and the nest was visited in the following days to collect the freshly laid third or fourth egg of each clutch.

Sampled populations were classified to represent coniferous, mixed or deciduous habitat (Table 1). Data from one population (Estonia) was collected from two habitats (coniferous and deciduous) which differ in some breeding parameters (e.g., Tilgar et al. 1999). In the analyses, these two were considered to be one population, but the habitat variable was different for the two subpopulations. Approximately 20 eggs were acquired per population to measure several maternal components, such as egg mass, yolk mass, albumen lysozyme enzyme activity, yolk immunoglobulin, and androgen concentrations (Ruuskanen et al., unpublished data). In all but two cases, 10 randomly chosen eggs were also measured for their yolk carotenoid profile. The eggs were stored at $-20^{\circ} \mathrm{C}$ until the laboratory 


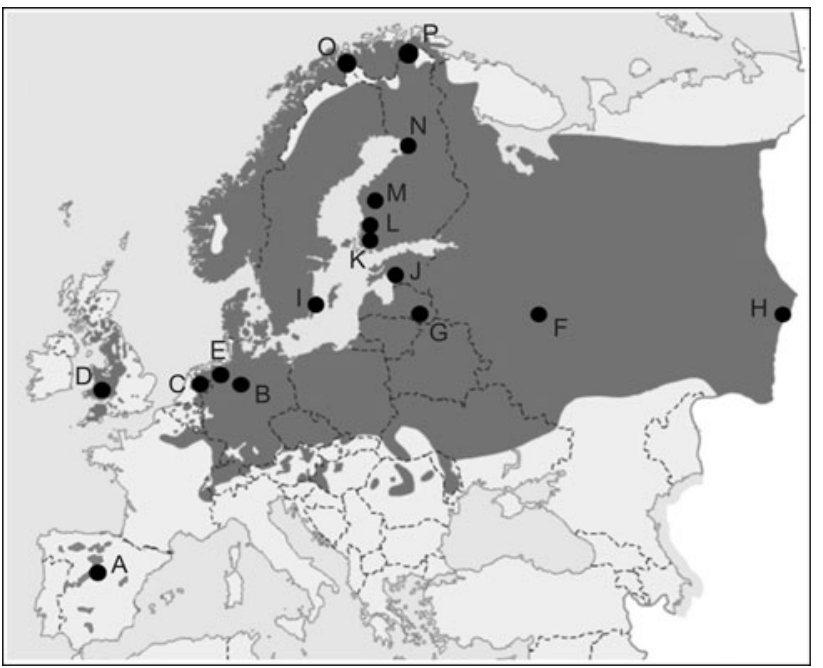

Fig. 1 A map showing the 16 populations from which Ficedula hypoleuca egg samples were collected for yolk carotenoid analyses. Letters refer to populations listed in Table 1. Gray area illustrates the breeding range of $F$. hypoleuca in Europe (map modified from OUP 2003)

analyses. Egg collection was conducted under licence from the environmental authority of each country.

\section{Carotenoid analyses}

Egg yolk was freeze-dried (at $-33^{\circ} \mathrm{C}$ for $48 \mathrm{~h}$ ) and ground into fine powder. A known amount of fine powder (approx. $20 \mathrm{mg}$ ) was extracted three times with $100 \%$ acetone. The solvent was evaporated from the combined extract under vacuum and the residue dissolved into a small volume of $100 \%$ acetone. The carotenoid composition of the extracts was analyzed with high-performance liquid chromatography (HPLC). The HPLC system (Merck-Hitachi, Tokyo, Japan) consisted of an L-7100 pump, an L-7400 UV detector, an L-7250 programmable autosampler, and a D-7000 interface. Selected samples were also analyzed using an L-7455 diode array detector. Merck-Hitachi model D-7000 chromatography data station software (version 3.1) was used. Sixty microliters of extract were injected into a YMC C-30 $(250 \times 4 \mathrm{~mm}$, i.d., $5 \mu \mathrm{m})$ column. Two solvents were used in the chromatography: (A) acetone/water (86:14, v/v) and (B) acetone. The gradient was: $0-15 \mathrm{~min}, 100 \%$ A (isocratic); $15-32 \mathrm{~min}, 100 \%$ A-100\% B (linear gradient); 32-60 min, 100\% B (isocratic). The flow rate used was $1.2 \mathrm{ml} / \mathrm{min}$. Carotenoids were detected at $450 \mathrm{~nm}$. Carotenoids were classified into two groups: carotenes and hydroxylated carotenes (i.e., xanthophylls). Due to their $\mathrm{OH}$ groups, the xanthophylls are more polar than carotenes and were thus eluted earlier than carotenes in the reversed-phase HPLC run. We identified two xanthophylls (lutein and zeaxanthin) by

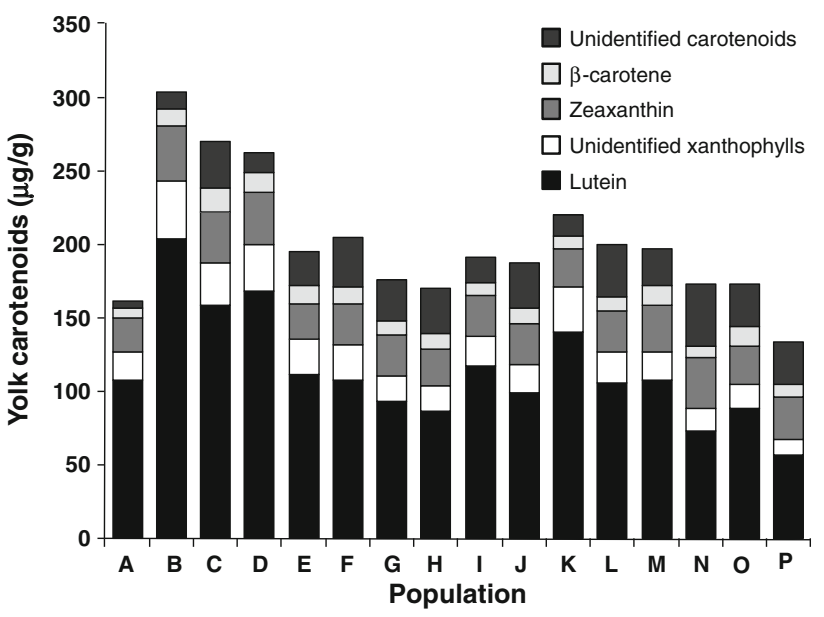

Fig. 2 Mean carotenoid concentrations (d.w.) in egg yolks of Ficedula hypoleuca in 16 European populations. Populations are sorted in ascending order according to latitude (see Fig. 1). Letters refer to the populations listed in Table 1

co-elution with commercial standards and by matching UV and mass spectra (Salminen et al., unpublished data). The other minor xanthophylls that eluted earlier than lutein and zeaxanthin had UV spectra of carotenoids and were thus classified as other xanthophylls. $\beta$-Carotene was similarly identified by co-elution with a commercial standard and by matching UV and mass spectra. The other carotenes that eluted close to $\beta$-carotene and had UV spectra of carotenoids were classified as unidentified carotenoids. $\beta$-Carotene was quantified using commercial $\beta$-carotene as a standard, and the other carotenoids (lutein, zeaxanthin, other xanthophylls and unidentified carotenoids) using commercial lutein as a standard.

\section{Statistical analyses}

We tested the relationships between yolk carotenoid concentrations (lutein, zeaxanthin, other xanthophylls, $\beta$-carotene, unidentified carotenoids and total; Fig. 2) and geographic location with generalized linear mixed models (GLMM) in the Glimmix procedure of SAS (SAS Institute 2003). The independent factors in the models were: latitude, longitude, altitude (m.a.s.l.), second-order terms of latitude and longitude, habitat (coniferous, mixed, deciduous), habitat $\times$ latitude and habitat $\times$ longitude. Altitude was included in the models as a confounding factor, since there was considerable variation in altitude among sampling sites (Table 1) and altitude may affect the diet of birds (e.g., via differences in vegetation and phenology). None of the carotenoid concentrations were correlated with clutch size ( $n=155, r=-0.081$ to $0.13, p>0.05$ in all) or yolk mass $(n=142, r=-0.11$ to $0.054, p>0.05$ in all), and these possible confounding variables were not 
included in the models. In these models, we used lognormal (to the base e) error distribution and population as random factors. Since some of our sampling sites were closer to one another than others, we first checked whether there was spatial autocorrelation in model residuals. Moran's $I$ coefficients ranged from -0.039 to -0.041 $(n=162)$, indicating a slight negative autocorrelation in the data. However, adding Gaussian or exponential spatial covariance structure to the models did not increase the model fit, as compared with the AIC values. Therefore, a default covariance structure (variance components) was used. Non-significant terms were dropped from the models one-by-one, starting from the interactions. The dropped main effects were again added to the reduced models one at a time, but in no case were they significant, and they were not included in the final models. Since our sample included both third and fourth eggs in laying order, we further checked if this variation in laying order explained any of the yolk carotenoid concentrations. We ran all the final models (lutein, zeaxanthin, other xanthophylls, $\beta$-carotene, unidentified carotenoids and total) with egg number added as a further explanatory factor. However, in no case was the effect of laying order significant. Degrees of freedom were calculated with the Kenward-Roger method. Pairwise post hoc comparisons between habitats were made with Tukey's test.

Because the proportions of five different carotenoid groups with respect to the total carotenoid concentration were intercorrelated and did not vary independently, we used principal component analysis (PCA) to calculate uncorrelated principal components (PC) from the carotenoid data. Before the PCA, a central logratio transformation $\left(x=\ln \left[\frac{x}{\bar{x}_{\mathrm{g}}}\right] ; \bar{x}_{\mathrm{g}}=\right.$ geometric mean of a proportion) was performed for carotenoid proportions to allow multivariate analysis on compositions (see Aitchison 1986). The first principal component explained $61 \%$ (eigenvalue $=3.1$ ) of the variation in the data. To study changes in carotenoid proportions, we used $\mathrm{PC} 1$ as a dependent factor in the same GLMM model as above, except that a normal error distribution was used.

As a post hoc analysis, we further tested whether the observed latitudinal variation in the carotenoid profile could be explained by latitudinal variation in concurrence between $F$. hypoleuca laying time and vegetation phenology. Since arboreal herbivores were found to be an important source of yolk carotenoids in a closely related species, F. albicollis (Hargitai et al. 2006; Török et al. 2007), we used Europe-wide phenological data on birch (Betula sp.) leaf unfolding dates published by Siljamo et al. (2008) as a measure of vegetation phenology. Since there were no large-scale data available for the sampling year (2007), we used the long-term (1970-2003) median leaf unfolding dates instead (Table 1). These values were compared with actual leaf unfolding dates for those eight populations for which we could find the estimate for 2007 (Table 1). The actual leaf unfolding dates differed by, on average, only $1.6(\mathrm{SD}=1.5, n=8)$ days from the longterm estimates, which suggests that it should be safe to use the long-term values in the analysis. For the most eastern population (H; Fig. 1), we used the actual value from 2007, since the study of Siljamo et al. (2008) did not extend there. Since it was obvious that the published estimates did not describe the environmental phenology of the Spanish highaltitude population very well (c.f. Sanz 2001), it was omitted from this analysis. For each $F$. hypoleuca nest, we calculated the difference between the laying date of the sampled egg and the median leaf unfolding date at the sampling site. We first tested with a GLMM whether this difference from the unfolding date depended on latitude (normal error distribution and population as a random factor). Next we ran a PCA for carotenoid concentrations to calculate uncorrelated PCs on five carotenoid groups. The first principal component explained $55 \%$ (eigenvalue $=2.7$ ) of the variation in the data. Finally, the difference between laying date and tree phenology was used as an explanatory variable together with habitat to explain PC1 of carotenoid concentrations in a GLMM (normal error distribution and population as random factors).

\section{Results}

\section{Carotenoid concentrations}

Mean yolk carotenoid concentrations in each population are shown in Fig. 2. The lutein concentrations of $F$. hypoleuca yolks showed a significant quadratic relationship with latitude: concentrations appeared to be moderate in the most southerly population (Spain), highest in Central Europe (i.e., $50-55^{\circ} \mathrm{N}$ ), and decreased again towards the north (Table 2; Fig. 3a). Lutein concentration was also significantly higher in deciduous than in coniferous forests (Tukey's test: $t=-3.94, d f=36.4, p=0.0052$ ), and marginally higher in deciduous than in mixed forests (Tukey's test: $t=2.59, d f=12.5, p=0.058$ ), while there was no difference between coniferous and mixed forests (Tukey's test: $t=-0.52, d f=11.3, p=0.86$ ). The interaction between latitude and habitat indicates that latitudinal decrease in lutein level was stronger in deciduous than in coniferous or mixed forests (Table 2; Fig. 3a). Unidentified xanthophylls showed very similar patterns to lutein relative to latitude and habitat, though there was no significant interaction between the two variables (Table 2; Fig. 3b). Other unidentified carotenoids showed an increasing quadratic trend towards the north (Table 2; 
Table 2 Results from generalized linear mixed models explaining geographical variation in individual and total carotenoid concentrations $(\mu \mathrm{g} / \mathrm{g}$, d.w.) in Ficedula hypoleuca egg yolk

\begin{tabular}{|c|c|c|c|c|c|c|}
\hline & \multicolumn{3}{|l|}{ Lutein } & \multicolumn{3}{|c|}{$\begin{array}{l}\text { Unidentified } \\
\text { xanthophylls }^{\mathrm{a}}\end{array}$} \\
\hline & $d f$ & $F$ & $p$ & $d f$ & $F$ & $p$ \\
\hline Latitude & $1,13.8$ & 12.2 & 0.0037 & $1,11.8$ & 7.9 & 0.016 \\
\hline Quadratic latitude & $1,13.9$ & 14.3 & 0.0021 & $1,11.9$ & 9.0 & 0.011 \\
\hline Habitat & $2,11.9$ & 5.1 & 0.026 & $2,18.7$ & 5.3 & 0.015 \\
\hline \multirow[t]{3}{*}{ Habitat $\times$ latitude } & $2,11.9$ & 4.6 & 0.033 & - & - & - \\
\hline & \multicolumn{3}{|c|}{ Unidentified carotenoids $^{\mathrm{b}}$} & \multicolumn{3}{|l|}{ Total } \\
\hline & $d f$ & $F$ & $p$ & $d f$ & $F$ & $p$ \\
\hline Latitude & $1,11.9$ & 6.6 & 0.025 & $1,12.9$ & 10.6 & 0.0064 \\
\hline Longitude & - & - & - & $1,12.0$ & 6.7 & 0.024 \\
\hline Quadratic latitude & $1,12.0$ & 4.8 & 0.049 & $1,13.1$ & 11.2 & 0.0052 \\
\hline Habitat & $2,18.8$ & 6.6 & 0.0068 & - & - & - \\
\hline
\end{tabular}

Generalized linear models with lognormal error distribution and population as a random factor. Global model: latitude, longitude, altitude, second-order terms of latitude and longitude, habitat (coniferous, mixed, deciduous), habitat $\times$ latitude and habitat $\times$ longitude. Non-significant terms were dropped from the models. None of the variables explained the variation in the concentrations of zeaxanthin and $\beta$-carotene

${ }^{\mathrm{a}}$ Unidentified $\quad$ xanthophylls $=$ total $\quad$ xanthophylls $\quad-$ (lutein + zeaxanthin)

${ }^{\mathrm{b}}$ Unidentified carotenoids $=$ total carotenoids - (total xanthophylls $+\beta$-carotene)

Fig. 3c). Their concentration was lower in deciduous forests than in mixed or coniferous forests (Tukey's test: deciduous vs. mixed: $t=-2.57, d f=13.7, p=0.047$; deciduous vs. coniferous: $t=3.47, \mathrm{df}=46.7, \quad p=$ $0.0069)$. Two of the carotenoids, zeaxanthin and $\beta$-carotene, showed no clear geographical trends (Fig 3d, e), and did not differ significantly among habitats $(p>0.05)$. The total carotenoid concentration showed a quadratic trend with latitude (Table 2; Fig. 3f), as well as a more linear decreasing trend from west to east (Table 2; figure not shown). Altitude did not significantly explain the variation in the concentrations of any of the carotenoids $(p>0.05)$.

\section{Carotenoid proportions}

The first principal component of the carotenoid proportions had negative loadings from lutein $(-0.53)$ and unidentified xanthophylls $(-0.50)$, while zeaxanthin $(0.37), \beta$-carotene $(0.29)$ and unidentified carotenoids $(0.50)$ showed positive loadings. PC1 was linearly and positively related to latitude (GLMM: $F_{1,12.8}=13.2, P=0.0028$; Fig. 4 ), but showed no clear longitudinal or altitudinal trends $(p>0.05)$. This result indicates that egg yolks in the south contain proportionally more lutein and unidentified xanthophylls than those in the north. The proportions of lutein and xanthophylls were correlated strongly and positively $\left(r_{\mathrm{s}}=0.69\right.$, $n=162$ ) with each other, but were negatively correlated with other carotenoids $\left(r_{\mathrm{s}}=-0.43\right.$ to $-0.94, n=162$ in all). Carotenoid profile also depended on habitat (GLMM: $F_{2,20.7}=5.57, P=0.012$ ), with $\mathrm{PC} 1$ being significantly lower in deciduous than in coniferous forests (Tukey's test: $t=3.14, d f=61.5, p=0.013)$. The result indicates that yolks in deciduous forests contain proportionally more lutein and unidentified xanthophylls than those in coniferous ones. The difference between deciduous and mixed forests was slightly higher, but not statistically significant (Tukey's test: $t=-2.31, d f=13.8, p=0.077$ ). There was no significant difference between coniferous and mixed habitats (Tukey's test: $t=-0.14, d f=12.6$, $p=0.99$ ).

Carotenoids and tree phenology

Tree phenology during laying was more advanced in southern than in northern populations: while some of the sampled eggs of the southerly populations were laid 27-35 days after the estimated birch leaf unfolding date, in the three most northern populations they were laid just 3-10 days after birch leafing (GLMM: $F_{1,13.9}=22.9$, $P=0.0003$ ). The first principal component of carotenoid concentrations had positive loadings from lutein $(0.57)$, unidentified xanthophylls (0.56), zeaxanthin (0.46) and $\beta$-carotene (0.38), while the unidentified carotenoids $(-0.10)$ showed weak negative loading. Carotenoid profile was associated with ambient tree phenology: PC1 of carotenoid concentrations was smaller in populations breeding early relative to birch leaf unfolding date (GLMM: $F_{1,51.5}=7.39, P=0.0089$; Fig. 5 ). This result indicates that eggs laid early relative to phenology contain less carotenoids, especially lutein and unidentified xanthophylls, than those laid later.

\section{Discussion}

We found that the concentrations and proportions of lutein and some other xanthophylls in egg yolks of $F$. hypoleuca decreased from Central Europe northwards. The most southern population (which was also that at the highest altitude), in Spain, also showed relatively low carotenoid concentrations, but still presented high proportion of lutein and some unidentified xanthophylls. The observed latitudinal trend in yolk carotenoid profiles supports our hypothesis that the increasing mismatch between the laying time and ambient phenology moving northwards would be reflected in egg yolk content. Very little is actually known about the laying time diet of $F$. hypoleuca, but since this 

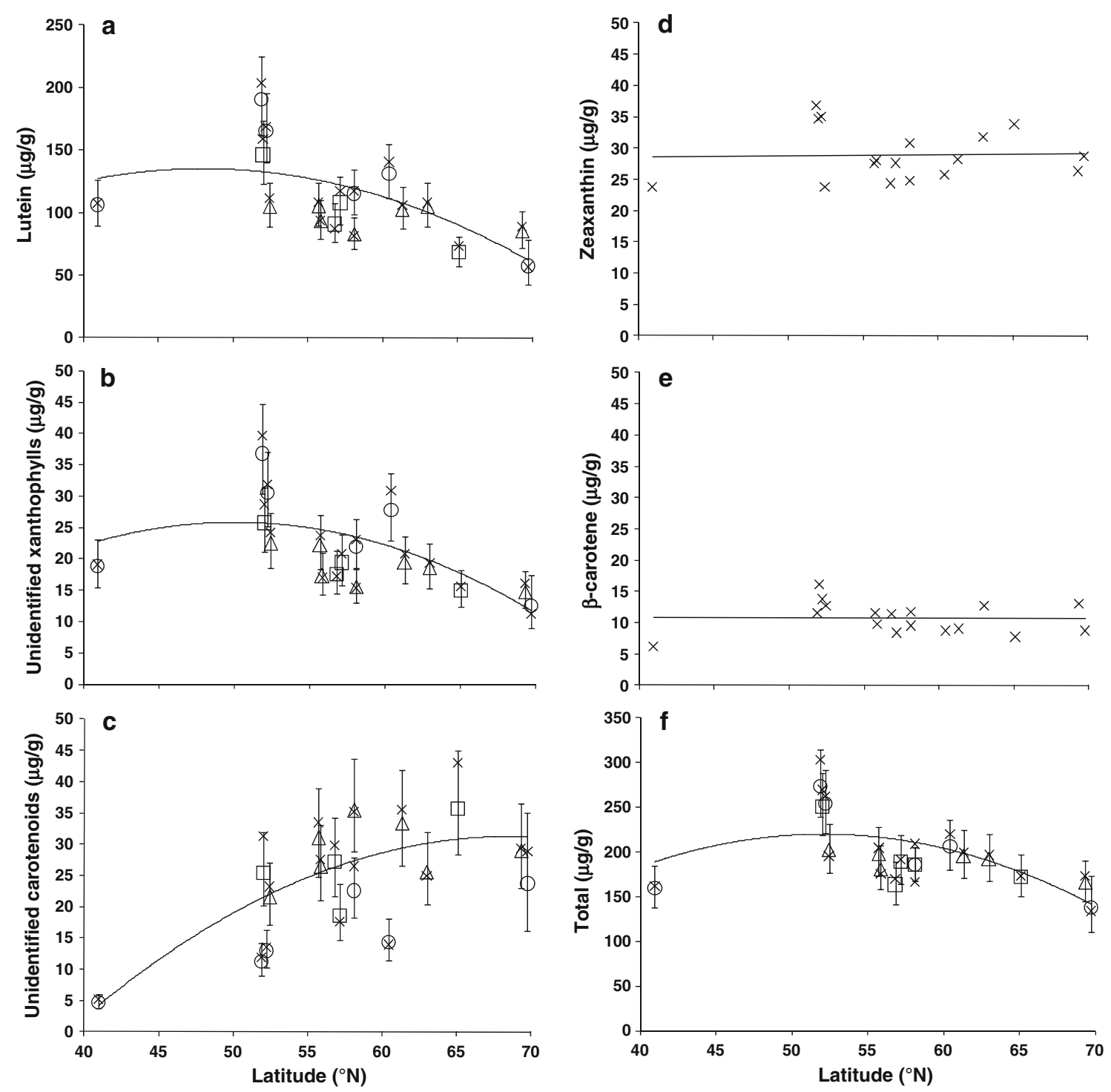

Fig. 3 Latitudinal variation in Ficedula hypoleuca egg yolk carotenoid concentrations (d.w.) across 16 European populations. Open symbols (triangles, coniferous; squares, mixed; circles, deciduous) show predicted values $( \pm 95 \%$ c.l.) from the GLMM models presented

in Table 2. Crosses show the actual population means with a regression line. Note that the variation in the predictions in Figs. 3, 4 and 5 is not residual variation but variation predicted by other factors in the model

species is very flexible in using different types of invertebrate prey, we consider it safe to assume that dietary proportions vary spatially according to which prey type is abundant at each site/time, as it is known to vary during the nestling phase (Lundberg and Alatalo 1992; Sanz 1998).

Northern populations of $F$. hypoleuca start laying earlier relative to the phenology of vegetation than southern ones (Lundberg and Alatalo 1992; our data). Northernmost populations start laying about the time of birch leafing, i.e. when lepidopteran caterpillars hatch and are still small. The larval periods of caterpillars, such as those of Operophtera sp. and Epirrita sp., vary with temperature, but normally last about 4-6 weeks (Tenow 1972; Ruohomäki

et al. 2000). It is obvious that the northernmost $F$. hypoleuca populations cannot rely on them as an important food source at the time of laying (see Eeva et al. 2000). Instead, populations in Central Europe start laying approximately 1-3 weeks before the caterpillar peak, and caterpillars are likely a more important component of food for $F$. hypoleuca females during laying, though their peak abundance coincides with chick feeding (Both and Visser 2005). Populations in Spain breed only at high altitudes $(>1,000$ m.a.s.l.), lay during the oak leafing period, and complete laying well before caterpillar availability reaches its peak (Sanz 2001; Sanz et al. 2003). They are thus more similar to northern than to Central European populations, which explains the quadratic trends in carotenoid 


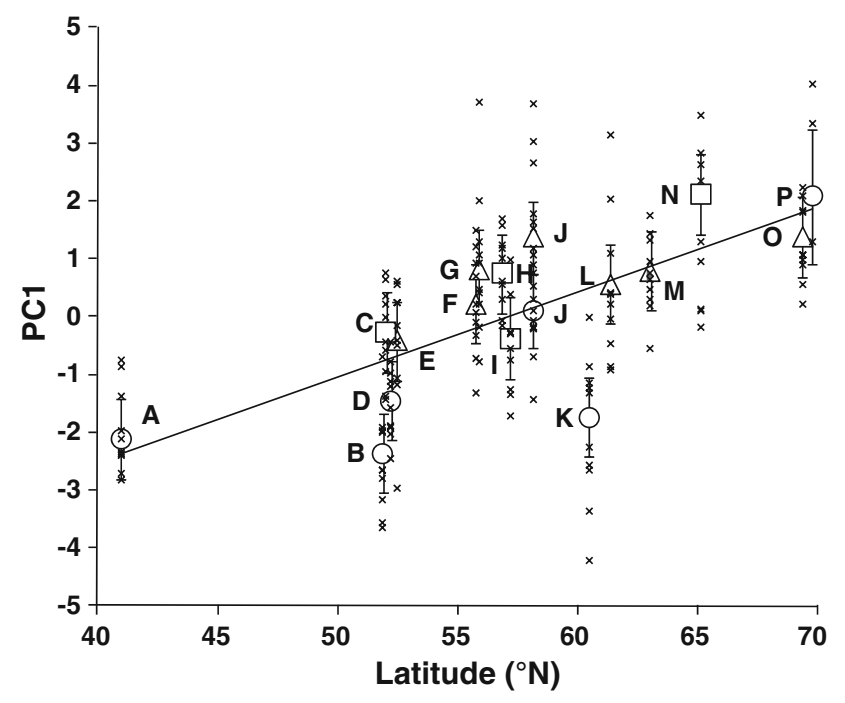

Fig. 4 Latitudinal variation in the first principal component for proportions of Ficedula hypoleuca yolk carotenoid concentrations (\% of the total concentration) in the egg yolks across 16 European populations. Open symbols (triangles, coniferous; squares, mixed; circles, deciduous) show predicted values ( $\pm 95 \%$ c.l.) from a GLMM model. Crosses show the actual population means with a regression line. Letters refer to the populations listed in Table 1

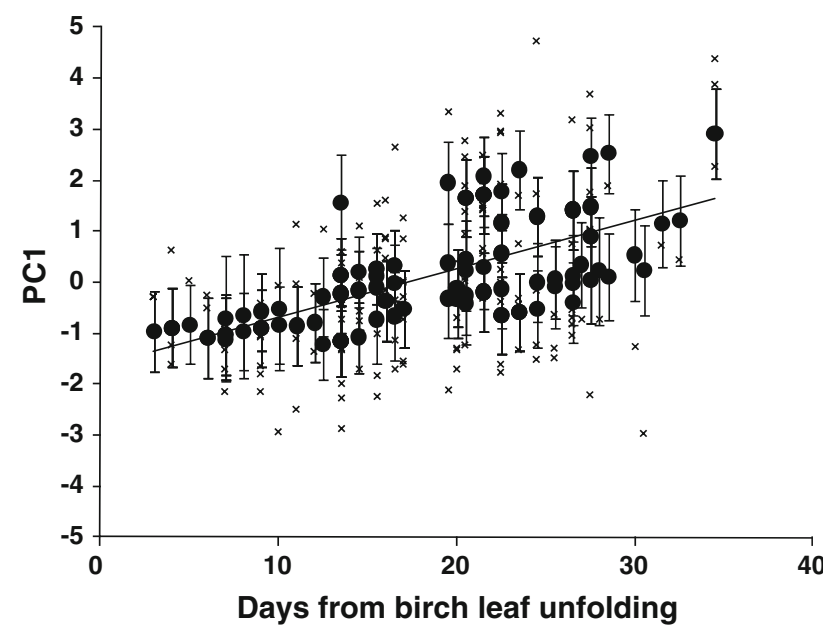

Fig. 5 The first principal component for Ficedula hypoleuca yolk carotenoid concentrations in relation to ambient vegetation phenology (birch leaf unfolding) at the time of laying. Data points are predicted values $( \pm 95 \%$ c.l.) from a GLMM model. Crosses show the actual values with a regression line

concentrations. The higher proportions of lutein and other xanthophylls in deciduous over coniferous forests could also be explained by higher caterpillar biomass in luxurious deciduous forests than in the more barren coniferous forests (van Balen 1973). At the Estonian study site, where eggs were collected from both habitats, deciduous forest did not, however, show higher caterpillar abundance at the time of $F$. hypoleuca laying, and later they were more abundant in the coniferous habitat, supposedly due to the lower density of birds there (Mägi et al. 2009; Remmel et al. 2009). Nevertheless, concentrations of lutein group carotenoids were still higher in the deciduous forest, suggesting that the different insect fauna present in the two habitats may have affected the levels observed in eggs (see below).

Lepidopteran larvae are known to contain relatively high amounts of carotenoids, especially lutein, which may comprise up to 80-90\% of total carotenoids (Partali et al. 1985; Eichenseer et al. 2002; Isaksson and Andersson 2007; Sillanpää et al. 2008; Eeva et al. 2010). The second main caterpillar group—sawflies (Symphyta)—also shows relatively high carotenoid contents, but a markedly different carotenoid profile, with sawflies containing proportionally much less (c.a. 24\%) lutein (Sillanpää et al. 2008). $F$. hypoleuca females are found to show an equal preference for both caterpillar groups (Atlegrim 1992). Spatial and temporal differences in the proportional abundances of these two caterpillar groups could therefore explain some of the variation in yolk carotenoid profiles across habitats (c.f. the Estonian population) and/or geographic range, though at least in the north the sawfly larvae may occur too late for them to be an important food item during the laying of $F$. hypoleuca (Eeva et al. 2000). Carotenoid concentrations in herbivorous insects may further vary according to their host plant. For example, concentrations tend to be lower in needles of coniferous trees than in leaves of deciduous trees (Czeczuga 1987). Such differences in plant carotenoid concentrations could be reflected in higher trophic levels, and may partly explain the lower yolk carotenoid concentrations of $F$. hypoleuca in coniferous habitats. On the other hand, no difference in carotenoid concentrations was found between birch (Betula verrucosa) and oak (Quercus robur) leaves, with birch species being important sources of caterpillars for northern populations and oaks for Central European populations (Isaksson 2009). Leaf carotenoid levels also respond to ambient light intensity, for example being generally higher at high-altitude sites (Tausz et al. 2003). In a study of Sillanpää et al. (2008), however, the quality of invertebrate diet was a more important determinant of carotenoid availability than variation in vegetation levels for an insectivorous bird, P. major.

Though generally acknowledged as very important, diet is not the only factor affecting carotenoid levels in birds (e.g., Cohen et al. 2009). Differences in absorption, usage or allocation could also produce spatial variations in yolk carotenoid levels and their relative proportions. Birds selectively absorb different carotenoids, and the absorbed ratio may vary according to diet. For example, despite an equal ratio of lutein and zeaxanthin in the diet, American goldfinches (Carduelis tristis) absorbed disproportionately more zeaxanthin than lutein at high carotenoid doses (McGraw et al. 2004). F. hypoleuca females may also 
differently allocate carotenoids and other important components to eggs at different parts of the species' geographical range or in different habitats. Other maternal resources, such as yolk androgens, are found to be correlated with yolk carotenoid concentrations, though the patterns vary among studies (Royle et al. 2001; Török et al. 2007). Geographical patterns in yolk androgen levels might thus produce corresponding patterns in carotenoid concentrations. Yolk steroid hormone levels do indeed increase in $F$. hypoleuca with latitude (the same populations sampled as here; Ruuskanen et al., unpublished data). However, this is not a likely reason for latitudinal variation in carotenoid levels, since there was no direct correlation between the two variables (Ruuskanen, unpublished data; see also Safran et al. 2008).

The roles of different carotenoids in embryonic development are not well understood (Surai et al. 2001), and currently we cannot ascertain whether the observed geographical trends in yolk carotenoid concentrations and carotenoid profile have any consequences for developing $F$. hypoleuca embryos or chicks. Different carotenoids are, however, known to have different physiological roles in their capacity to act as antioxidants and immune stimulants. Among them, carotenes (e.g., $\beta$-carotene) are found to show a higher reactive oxygen species (ROS) scavenging capacity than xanthophylls (Pérez-Rodríguez 2009). For example, lutein, the primary carotenoid in the diets and plasma of many bird species (see McGraw 2006), is a xanthophyll that is suggested to have a minor role as an antioxidant (Hartley and Kennedy 2004; Török et al. 2007; Costantini and Møller 2008; Isaksson et al. 2008). In our study, lutein and some other xanthophylls showed decreasing latitudinal trends, while the two more potent antioxidants (see Mortensen and Skibsted 1997), $\beta$-carotene and zeaxanthin, did not show any geographical trends. The deposition of strong antioxidants into yolk may be physiologically more strictly regulated than that of less potent antioxidants. For example, $\beta$-carotene is one of the most powerful antioxidants, but it can become a pro-oxidant above threshold concentrations (Blount et al. 2002). Therefore, its relatively constant level among populations might reflect a more strict physiological adjustment. The concentration of unidentified carotenoids increased towards the north. Since birds absorb oxycarotenoids like lutein very effectively, the increasing amount of unidentified carotenoids may just mirror the decreasing dietary concentration of lutein. Therefore, we consider it unlikely that egg yolks of northern populations would have less efficient antioxidant protection when it comes to carotenoids. Other possible fitness consequences (changes in immune defense, growth, survival, sex ratio, etc.) warrant further studies.

Our study shows that there is large-scale geographic and among-habitat variation in an important maternal component of $F$. hypoleuca eggs. To our knowledge, largescale geographical gradients in yolk carotenoid profiles have not been described earlier. We suggest that these patterns could be explained by dietary differences across latitude and among habitats. In the future, it will be important to measure female diet compositions in different populations at or before laying in order to get more information on the mechanism. Prominent geographic variation in invertebrate fauna as well as in tree species composition may also produce large-scale patterns in yolk concentrations. To some extent, the carotenoid compositions of herbivorous insects likely reflect the carotenoid compositions of their host plants. We are not aware of any large-scale comparisons of variation in vegetation or invertebrate carotenoid profiles. Such information would shed light on possible sources of variation observed in birds. Recent manipulations have revealed that experimentally increased yolk carotenoid levels may enhance embryonic survival (McGraw et al. 2005), speed up the growth and development of the immune system (Saino et al. 2003, Biard et al. 2005, 2007) and produce sexrelated effects of maternal investment on offspring (McGraw et al. 2005, Berthouly et al. 2008). Further studies are needed to test the role of adaptive variation in yolk carotenoid levels and possible fitness consequences of the observed geographical variation in F. hypoleuca.

Acknowledgments Three anonymous referees are warmly acknowledged for valuable comments on the manuscript. This study was financially supported by the Turku University Foundation, the Finnish Cultural Foundation (grants to S.R. and T.E), the Emil Aaltonen Foundation (a grant to T.L.) and the Academy of Finland (to T.E., project 8119367). J.M. was supported by grant CGL2007-61251 from CICYT, Spain. Data collection in the Moscow region was supported by the Russian Foundation of Basic Research (RFBR). R.M. and V.T. were supported by grant 6908 from the Estonian Science Foundation and the target-financing project 0180004s09 from the Estonian Ministry of Education and Science. E.B. was financed by a program for the support of Scientific-Educational Centers (contract 02.740.11.0279). H.S. was supported by the Academy of Finland (project 7119165). M.O. was supported by a grant from Thule Institute of the University of Oulu. We thank lab technicians at the University of Jyväskylä, Kevo Subarctic Research Station, and all of the field assistants for providing help.

\section{References}

Aitchison J (1986) The statistical analysis of compositional data. Chapman and Hall, London

Atlegrim O (1992) Mechanisms regulating bird predation on a herbivorous larva guild in boreal coniferous forests. Ecography 15:19-24

Berthouly A, Helfenstein F, Tanner M, Richner H (2008) Sex-related effects of maternal egg investment on offspring in relation to carotenoid availability in the great tit. J Anim Ecol 77:74-82

Biard C, Surai PF, Møller AP (2005) Effects of carotenoid availability during laying on reproduction in the blue tit. Oecologia 144:32-44 
Biard C, Surai PF, Møller AP (2007) An analysis of pre- and posthatching maternal effects mediated by carotenoids in the blue tit. J Evol Biol 20:326-339

Blount JD, Houston DC, Møller AP (2000) Why egg yolk is yellow. TREE 15:47-49

Blount JD, Surai PF, Houston DC, Møller AP (2002) Patterns of yolk enrichment with dietary carotenoids in gulls: the roles of pigment acquisition and utilization. Funct Ecol 16:445-453

Blount JD, Houston DC, Surai PF, Møller AP (2004) Egg-laying capacity is limited by carotenoid pigment availability in wild gulls Larus fuscus. Proc R Soc Lond B Biol Sci 271:S79-S81

Both C, Visser ME (2005) The effect of climate change on the correlation between avian life-history traits. Glob Change Biol 11:1606-1613

Cassey P, Ewen JG, Boulton RL, Blackburn TM, Moller AP, Biard C, Olson V, Karadas F (2005) Egg carotenoids in passerine birds introduced to New Zealand: relations to ecological factors, integument coloration and phylogeny. Funct Ecol 19:719-726

Cohen AA, McGraw KJ, Robinson WD (2009) Serum antioxidant levels in wild birds vary in relation to diet, season, life history strategy, and species. Oecologia 161:673-683

Costantini D, Møller AP (2008) Carotenoids are minor antioxidants for birds. Funct Ecol 22:367-370

Czeczuga B (1987) The effect of light on the content of photosynthetically active pigments in plants.10. Carotenoid contents in leaves grown under various light intensities. Biochem Syst Ecol 15:523-527

Eeva T, Veistola S, Lehikoinen E (2000) Timing of breeding in subarctic passerines in relation to food availability. Can $\mathrm{J}$ Zool 78:67-78

Eeva T, Lehikoinen E, Rönkä M, Lummaa V, Currie D (2002) Different responses to cold weather in two pied flycatcher populations. Ecography 25:705-713

Eeva T, Ryömä M, Riihimäki J (2005) Pollution-related changes in diets of two insectivorous passerines. Oecologia 145:629-639

Eeva T, Helle S, Salminen J-P, Hakkarainen H (2010) Carotenoid composition of dietary invertebrates in two insectivorous bird species. J Chem Ecol 36:608-613

Eichenseer H, Murphy JB, Felton GW (2002) Sequestration of host plant carotenoids in the larval tissues of Helicoverpa zea. J Insect Physiol 48:311-318

Gibb JA, Betts MM (1963) Food and food supply of nestling tits (Paridae) in Breckland pine. J Anim Ecol 32:489-533

Hargitai R, Matus Z, Hegyi G, Michl G, Toth G, Török J (2006) Antioxidants in the egg yolk of a wild passerine: differences between breeding seasons. Comp Biochem Physiol B Biochem Mol Biol 143:145-152

Hartley RC, Kennedy MW (2004) Are carotenoids a red herring in sexual display? TREE 19:353-354

Hõrak P, Surai PF, Møller AP (2002) Fat-soluble antioxidants in the eggs of great tits Parus major in relation to breeding habitat and laying sequence. Avian Sci 2:123-130

SAS Institute (2003) The SAS system for Windows (release 9.1). SAS Institute, Cary

Isaksson C (2009) The chemical pathway of carotenoids: from plants to birds. Ardea 97:125-128

Isaksson C, Andersson S (2007) Carotenoid diet and nestling provisioning in urban and rural great tits Parus major. J Avian Biol 38:564-572

Isaksson C, Johansson A, Andersson S (2008) Egg yolk carotenoids in relation to habitat and reproductive investment in the great tit Parus major. Physiol Biochem Zool 81:112-118

Järvinen A (1983) Breeding strategies of hole-nesting passerines in northern Lapland. Ann Zool Fennici 20:129-149

Järvinen A (1993) Spatial and temporal variation in the reproductive traits of adjacent northern pied flycatcher Ficedula hypoleuca populations. Ornis Scand 24:33-40
Koutsos EA, Lopez JCG, Klasing KC (2006) Carotenoids from in ovo or dietary sources blunt systemic indices of the inflammatory response in growing chicks (Gallus gallus domesticus). J Nutr 136:1027-1031

Lundberg A, Alatalo RV (1992) The pied flycatcher. T \& AD Poyser, London

Mägi M, Mänd R, Tamm H, Sisask E, Kilgas P, Tilgar V (2009) Low reproductive success of great tits in the preferred habitat: a role of food availability. Ecoscience 16:145-157

McGraw KJ (2006) Mechanics of carotenoid-based coloration. In: Hill GE, McGraw KJ (eds) Bird coloration. I: Mechanisms and measurements. Harvard University Press, Cambridge, pp 177-242

McGraw KJ, Hill GE, Navara KJ, Parker RS (2004) Differential accumulation and pigmenting ability of dietary carotenoids in colorful finches. Physiol Biochem Zool 77:484-491

McGraw KJ, Adkins-Regan E, Parker RS (2005) Maternally derived carotenoid pigments affect offspring survival, sex ratio, and sexual attractiveness in a colorful songbird. Naturwissenschaften 92:375-380

Mortensen A, Skibsted LH (1997) Importance of carotenoid structure in radical-scavenging reactions. J Agr Food Chem 45:2970-2977

OUP (2003) Birds of the Western Palearctic, version 2.0.1. Oxford University Press, Oxford

Partali V, Liaaen-Jensen S, Slagsvold T, Lifjeld JT (1985) Carotenoids in food chain studies-II. The food chain of Parus spp. monitored by carotenoid analysis. Comp Biochem Physiol B Biochem Mol Biol 82:767-772

Pérez-Rodríguez L (2009) Carotenoids in evolutionary ecology: reevaluating the antioxidant role. Bioessays 31:1116-1126

Perrins CM (1991) Tits and their caterpillar food supply. Ibis 133:49-54

Remes V, Krist M, Bertacche V, Stradi R (2007) Maternal carotenoid supplementation does not affect breeding performance in the great tit (Parus major). Funct Ecol 21:776-783

Remmel T, Tammaru T, Mägi M (2009) Seasonal mortality trends in tree-feeding insects: a field experiment. Ecol Entomol 34:98-106

Royle NJ, Surai PF, McCartney RJ, Speake BK (1999) Parental investment and egg yolk lipid composition in gulls. Funct Ecol 13:298-306

Royle NJ, Surai PF, Hartley IR (2001) Maternally derived androgens and antioxidants in bird eggs: complementary but opposing effects? Behav Ecol 12:381-385

Ruohomäki K, Tanhuanpää M, Ayres MP, Kaitaniemi P, Tammaru T, Haukioja E (2000) Causes of cyclicity of Epirrita autumnata (Lepidoptera, Geometridae): grandiose theory and tedious practice. Popul Ecol 42:211-223

Safran RJ, Pilz KM, McGraw KJ, Correa SM, Schwabl H (2008) Are yolk androgens and carotenoids in barn swallow eggs related to parental quality? Behav Ecol Sociobiol 62:427-438

Saino N, Bertacche V, Ferrari RP, Martinelli R, Møller AP, Stradi R (2002) Carotenoid concentration in barn swallow eggs is influenced by laying order, maternal infection and paternal ornamentation. Proc R Soc Lond B Biol Sci 269:1729-1733

Saino N, Ferrari R, Romano M, Martinelli R, Møller AP (2003) Experimental manipulation of egg carotenoids affects immunity of barn swallow nestlings. Proc R Soc Lond B Biol Sci 270:2485-2489

Sanz JJ (1998) Effect of habitat and latitude on nestling diet of pied flycatchers Ficedula hypoleuca. Ardea 86:81-88

Sanz JJ (2001) Experimentally increased insectivorous bird density results in a reduction of caterpillar density and leaf damage to Pyrenean oak. Ecol Res 16:387-394

Sanz JJ, Potti J, Moreno J, Merino S, Frias O (2003) Climate change and fitness components of a migratory bird breeding in the Mediterranean region. Glob Change Biol 9:461-472 
Siljamo P, Sofiev M, Ranta H, Linkosalo T, Kubin E, Ahas R, Genikhovich E, Jatczak K, Jato V, Nekovar J, Minin A, Severova E, Shalaboda V (2008) Representativeness of pointwise phenological Betula data collected in different parts of Europe. Glob Ecol Biogeogr 17:489-502

Sillanpää S, Salminen J-P, Lehikoinen E, Toivonen E, Eeva T (2008) Carotenoids in a food chain along a pollution gradient. Sci Tot Environ 406:247-255

Sillanpää S, Salminen J-P, Eeva T (2009) Breeding success and lutein availability in great tit (Parus major). Acta Oecol 35:805-810

Slagsvold T (1975) Breeding time of birds in relation to latitude. Norw J Zool 23:213-218

Slagsvold T (1976) Annual and geographical variation in the time of breeding of the great tit Parus major and the pied flycatcher Ficedula hypoleuca in relation to environmental phenology and spring temperature. Ornis Scand 7:127-145

Surai PF, Speake BK, Sparks NHC (2001) Carotenoids in avian nutrition and embryonic development. 1. Absorption, availability and levels in plasma and egg yolk. J Poultry Sci 38:1-27

Tausz M, Wonisch A, Grill D, Morales D, Jimenez MS (2003) Measuring antioxidants in tree species in the natural environment: from sampling to data evaluation. J Exp Bot 54: $1505-1510$

Tenow O (1972) The outbreaks of Oporinia autumnata Bkh. and Operophtera spp. (Lep. Geometridae) in the Scandinavian mountain chain and northern Finland 1862-1968. Zool Bidr Upps Suppl 2:1-107

Tilgar V, Mänd R, Leivits A (1999) Effect of calcium availability and habitat quality on reproduction in pied flycatcher Ficedula hypoleuca and great tit Parus major. J Avian Biol 30:383-391

Török J, Hargitai R, Hegyi G, Matus Z, Michl G, Péczely P, Rosivall B, Tóth G (2007) Carotenoids in the egg yolks of collared flycatchers (Ficedula albicollis) in relation to parental quality, environmental factors and laying order. Behav Ecol Sociobiol 61:541-550

Tummeleht L, Mägi M, Kilgas P, Mänd R, Hõrak P (2006) Antioxidant protection and plasma carotenoids of incubating great tits (Parus major L.) in relation to health state and breeding conditions. Comp Biochem Physiol C Toxicol Pharmacol 144:166-172

van Balen JH (1973) A comparative study of the breeding ecology of the great tit Parus major in different habitats. Ardea 61:1-93

van Dongen S, Backeljau T, Matthysen E, Dhondt AA (1997) Synchronization of hatching date with budburst of individual host trees (Quercus robur) in the winter moth (Operophtera brumata) and its fitness consequences. J Anim Ecol 66:113-121

van Noordwijk AJ, McCleery RH, Perrins CM (1995) Selection for the timing of great tit breeding in relation to caterpillar growth and temperature. J Anim Ecol 64:451-458 